\title{
A RIEMANNN SURFACE APPROACH FOR DIFFRACTION FROM RATIONAL WEDGES
}

\author{
T. Ehrhardt, A. P. Nolasco And F.-O. SpeCK
}

\begin{abstract}
This paper aims at the explicit analytical representation of acoustic, electromagnetic or elastic, time-harmonic waves diffracted from wedges in $\mathbb{R}^{3}$ in a correct setting of Sobolev spaces. Various problems are modelled by Dirichlet or Neumann boundary value problems for the $2 D$ Helmholtz equation with complex wave number. They have been analyzed before by several methods such as the Malinzhinets method using Sommerfeld integrals, the method of boundary integral equations from potential theory or Mellin transformation techniques. These approaches lead to results which are particularly useful for asymptotic and numerical treatment. Here we develop new representation formulas of the solutions which are based upon the solutions to Sommerfeld diffraction problems. We make use of symmetry properties, which require a generalization of these formulas to Riemann surfaces in order to cover arbitrary rational angles of the wedge. The approach allows us to prove well-posedness in suitable Sobolev spaces and to obtain explicit solutions in a new, perhaps surprising, form provided the angle is rational, i.e., $\alpha=\pi m / n$ where $m, n \in \mathbb{N}$.
\end{abstract}

Mathematics subject classification (2010): 35J05, 78A45, 45E10, 47B35.

Keywords and phrases: Wedge diffraction problem, Helmholtz equation, boundary value problem, Sommerfeld potential, conical Riemann surface.

\section{REFERENCES}

[1] L. P. CASTRO AND D. KAPANADZE, Wave diffraction by a 45 degree wedge sector with Dirichlet and Neumann boundary conditions, Mathematical and Computer Modelling, 48 (2008), 114-121.

[2] L. P. Castro And D. Kapanadze, Exterior wedge diffraction problems with Dirichlet, Neumann and impedance boundary conditions, Acta Appl. Math., 110 (2010), 289-311.

[3] L. P. CASTRO AND F.-O. SPECK, On the inversion of higher order Wiener-Hopf operators, J. Integral Equations Appl. 8 (1996), 269-285.

[4] L. P. CASTRO AND F.-O. SPECK, Regularity properties and generalized inverses of delta-related operators, Z. Anal. Anwend. 17 (1998), 577-598.

[5] L. P. CASTRO, F.-O. SPECK AND F. S. TeIXeIRA, On a class of wedge diffraction problems posted by Erhard Meister, Oper. Theory Adv. Appl. 147 (2004), 211-238.

[6] L. P. CASTRO, F.-O. SPECK AND F. S. TeIXEIRA, A direct approach to convolution operators with symmetry, Math. Nachr. 269-270 (2004), 73-85.

[7] T. EhrHARDT, A. P. NOLASCO AND F.-O. SPECK, Boundary integral methods for wedge diffraction problems: the angle $2 \pi / n$, Dirichlet and Neumann conditions, Operators and Matrices 5 (2011), $1-40$.

[8] G. I. ÈsKIn, Boundary Value Problems for Elliptic Pseudodifferential Equations, Translations of Mathematical Monographs 52, AMS, Providence, R. I., 1981.

[9] A. E. HEINS, The Sommerfeld half-plane problem revisited, II, the factoring of a matrix of analytic functions, Math. Meth. Appl. Sci. 5 (1983), 14-21.

[10] G. C. Hsiao And W. L. Wendland, Boundary Integral Equations, Applied Mathematical Sciences Series 164, Springer-Verlag, Berlin 2008.

[11] A. I. Komech, N. J. Mauser And A. E. Merzon, On Sommerfeld representation and uniqueness in scattering by wedges, Math. Meth. Appl. Sci. 28 (2005), 147-183. 
[12] E. MEISTER, Ein Überblick über analytische Methoden zur Lösung singulärer Integralgleichungen, in: Proceedings of the GAMM Conference in Graz in 1976, Z. Angew. Math. Mech. 57 (1977), T23$\mathrm{T} 35$.

[13] E. MeISTER, Some multiple-part Wiener-Hopf problems in Mathematical Physics, in: Mathematical Models and Methods in Mechanics, Banach Center Publications 15, PWN - Polish Scientific Publishers, Warsaw (1985) 359-407.

[14] E. Meister, F. PenZel, F.-O. Speck And F. S. Teixeira, Some interior and exterior boundaryvalue problems for the Helmholtz equation in a quadrant, Proc. R. Soc. Edinb., Sect. A 123 (1993), 193-237.

[15] E. Meister And F.-O. SPECK, Modern Wiener-Hopf methods in diffraction theory, Pitman Res. Notes Math. Ser. 216 (1989), 130-171.

[16] A. Merzon, F.-O. Speck And T. Villalba-Vega, On the weak solution of the Neumann problem for the $2 D$ Helmholtz equation in a convex cone and $H^{s}$ regularity, Math. Meth. Appl. Sci. 34 (2011), $24-43$.

[17] A. Moura Santos, F.-O. Speck And F. S. Teixeira, Minimal normalization of Wiener-Hopf operators in spaces of Bessel potentials, J. Math. Anal. Appl. 225 (1998), 501-531.

[18] R. J. Nagem, M. Zampolli And G. SAndRI, Arnold Sommerfeld: Mathematical Theory of Diffraction, Birkhäuser, Basel, 2004.

[19] A. P. Nolasco AND F.-O. SPECK, On some boundary value problems for the Helmholtz equation in a cone of $240^{\circ}$, In: Spectral Theory, Mathematical System Theory, Evolution Equations, Differential and Difference Equations, Proceedings of the IWOTA 2010 at Berlin (Eds. W. Arendt, J. A. Ball, K.-H. Förster, V. Mehrmann, C. Trunk), Birkhäuser OTAA series, Vol. 221, Springer, Basel 2012, 509-525.

[20] A. V. OSIPOV AND A. N. NORRIS, The Malyuzhinets theory for scattering from wedge boundaries: a review, Wave Motion 29 (1999), 313-340.

[21] A. D. Rawlins, The explicit Wiener-Hopf factorization of a special matrix, Z. Angew. Math. Mech. 61 (1981), 527-528.

[22] A. D. RAWLINS, The solution of a mixed boundary value problem in the theory of diffraction, J. Eng. Math. 18 (1984), 37-62. 
[23] S. G. Sommerfeld, Mathematische Theorie der Diffraction, Math. Annalen 47 (1896), 317-374.

[24] F.-O. SPECK, Mixed boundary value problems of the type of Sommerfeld's half-plane problem, Proc. Royal Soc. Edinburgh 104 A (1986), 261-277.

[25] P. Ya. Ufimtsev, Theory of Edge Diffraction in Electromagnetics, Tech Science Press, Encino, California, 2003. 